\title{
An Analysis of Thai Student Teacher Appropriate Internet Use Behaviour
}

\author{
https://doi.org/10.3991/ijet.v16i02.13747 \\ Punnee Leekitchwatana, Paitoon Pimdee ${ }^{(\bowtie)}$ \\ King Mongkut's Institute of Technology Ladkrabang (KMITL), \\ Bangkok, Thailand \\ paitoon.pi@kmitl.ac.th
}

\begin{abstract}
The goals of this research were to analyse and develop a Hierarchical Linear Model (HLM) of appropriate Internet use behaviour of Thai student teachers. The sample group consisted of 1,800 student teachers studying for their bachelor's degree at 30 Thai government educational institutions. The research tool used was a questionnaire with content validity and reliability at $0.83-0.92$. Mean $(\bar{x})$, standard deviation (S.D.), and HLM were used to analyse the data. The findings revealed that appropriate Internet use behaviour in Thai student teachers was at a high level. Additionally, the HLM for appropriate Internet use behaviour for Thai student teachers consisted of two levels of predictor variables. The first level was the student teacher level, in which six of the hypothesized nine predictor variables had statistical significance. Five had a positive effect, which included ability, affect, family situation, gender, and GPA, while one variable had a negative effect, which was income. The second level was the institutional level, which contained two predictor variables with statistical significance, friends and educational institution situation, with both having positive effects. Friends had a direct effect on behaviour at the educational institution level, while educational institution situation had an effect through ability.
\end{abstract}

Keywords - Hierarchical Linear Model, Internet addiction, Internet behaviour, Thailand

\section{Introduction}

Advances in technology play significant roles in peoples' lives, in terms of study, work, and daily life. For this reason, educational institutions adjust their instructional patterns to gain more benefits from information technology, whereas learners adapt their learning approaches by using more information technology [1]. However, problems arising from excessive Internet use have been documented worldwide, including in Thailand, where the use of the Internet has increased noticeably and Internet addiction (IA) has become a serious social problem [2] - [5].

Fortunately, the use of the Internet for learning is the key educational innovation in the modern world and a pillar for sustainable development [6]. Learners in formal and non-formal educational systems, as well as those in self-learning systems, have more 
of a chance to learn from the Internet [7]. However, there are a multitude of factors which have been identified over the years since the Internet's introduction as what constitute a learner's appropriate Internet use behaviour [8].

In Russia, a study was conducted on college students and discovered that $60 \%$ used the Internet for school-related activities, followed by e-mail (55\%), entertainment (50\%), chatting (24\%), and searching for pornography (6\%) [9]. The students also reported that Internet use for downloading illegal and pirated items such as movies and music was an acceptable activity. Other examples include a learner's personal characteristics and background, such as psychological factors, and external factors, such as surroundings. This is consistent with [10], who stated that problematic Internet use is potentially high in individuals who have previously shown a history of impulse control problems and addictive disorders.

Student teachers as a group are very familiar with the Internet today and are therefore expected to use this technological medium with professional care in teaching and life. It has also been added that a pre-service teacher's mentor plays a critical role in how much or how little technology a student teacher will use in their own classroom [11]. Therefore, appropriate Internet use behaviour in student teachers is considered a vital behaviour trait which needs to be examined, to see whether they currently have appropriate Internet use behaviour or not, and what variables cause their behaviour, and how these variables are related.

For this reason, the researchers would like to study appropriate Internet use behaviour in student teachers from which a causal relationship model is planned. An HLM is proposed for the study as it is an excellent tool for data analysis when data is nested where groups of units are clustered together in an organized fashion, such as students within classrooms within schools (as is the case with the proposed study) [12]. Also, an HLM can analyze the collected data of each level separately, which helps the researcher find out the effect of the independent and dependent variables at each level [13]. In this research, the researchers identified independent variables at two levels; the unit level, which was the student level, and the group level, which was the educational institution level. Also, independent variables involved with student teacher internal and external variables were examined [14] - [15].

This is consistent with a Thai student study in which human behaviour was examined from both internal and external factors [16]. Furthermore, student background was examined as an independent variable, while Internet use was the dependent variable. Results stated that Internet use learning behaviour and ethical use were two factors which contributed to the most appropriate use of the Internet.

Therefore, it is hoped that this study's research findings concerning student teachers' appropriate Internet use behaviour will help in giving valuable information and new knowledge helpful to the development planning of student teacher appropriate Internet use behaviour. 


\subsection{Research objectives}

- To examine the level of appropriate Internet use behaviour of Thai student teachers.

- To study the variables at the student teacher level that has an influence on the appropriate Internet use behaviour of Thai student teachers.

- To study the variables at the school level that has an influence on the appropriate Internet use behaviour of Thai student teachers.

\subsection{Hypotheses}

- Student variables include ability, affect, family situation, gender, age, programme, GPA, income, and experience which influence appropriate Internet use behaviour of Thai student teachers.

- The variables at the school level consist of the educational institute situation, professors, and friends which influence appropriate Internet use behaviour of Thai student teachers.

\section{Framework}

\subsection{Aspects affecting Thai student teacher appropriate internet use behaviour at the student teacher level}

In a study related to dysfunctional Internet use (DIU) [17], it was determined that both Internet addiction (IA) and cyberbullying (CB) had frequent negative outcomes. Furthermore, younger users and less conscientious users were more likely to use the Internet dysfunctionally. Additional research also determined that the Internet becomes a source of self-medication for younger users, especially in the process of developing identities or establishing relationships [18]. Even when Internet use is beneficial, abnormal use can have negative consequences on an individual and other users over extended periods of time [19].

Furthermore, the Unified Theory of Acceptance and Use of Technology (UTAUT) was used to examine E-learning systems and technologies in various educational environments [20]. Results from the study determined that social influence and performance expectancy significantly influence the intention to use the technology. However, there was no significant influence found in either a student's prior education or their sex.

Also, in China, an investigation of Internet use by Chinese faculty, researchers, and students determined that more men than women used the Internet, with individuals having obtained higher degrees, and those who were younger were predisposed to spend more time on the Internet [21].

Therefore, from the review of the literature and theory, the authors added ability, affect, family, gender, age, programme, GPA, income and experience as potential aspects influencing appropriate Internet use behaviour at the student teacher level. 


\subsection{Aspects affecting Thai student teacher appropriate internet use behaviour at the institutional level}

Numerous studies discuss the importance of the Internet used by academic staff at institutions worldwide. Over the years, as connectivity and speed has increased, academics have moved from just using the Internet to far more robust applications such as blended learning, often times associated with learning management systems. However, there can be a darker side to Internet use. These dark side elements can include Internet addiction, cyber-bullying, pornography, online gambling, and relationship abuse, sexual harassment, and stalking [3] - [5], [22] - [23].

Furthermore, Internet and social media use among Thais has exploded, especially in the age group between 13 and 24 years old. Daily Internet usage rates continue to soar, with a 2019 study stating that Thais used the Internet 9 hours 11 minutes per day, while spending 3 hours 11 minutes per day on social media platforms [24]. However, does this heavy usage carry over to student teachers, and if so, is its appropriate use?

Therefore, from the review of the literature and theory, the authors added the student teacher's educational institute situation, their professors, and friends as potential aspects influencing appropriate Internet use behaviour at the student teacher institutional level.

\subsection{The Hierarchical Linear Model (HLM)}

Therefore, from the short overview of the variables affecting Thai student teacher Internet behaviour, the HLM as a causal relationship between the independent variables at the student and educational institution level, as well as the dependent variable of appropriate Internet use behaviour of Thai student teachers is depicted in Figure 1 [1], [17], [20], [25].

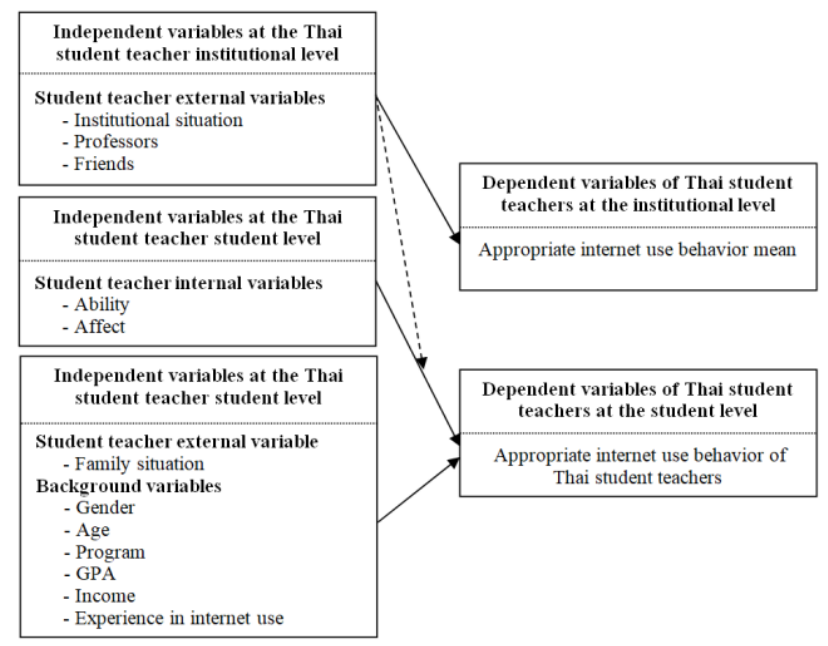

Fig. 1. Conceptual framework for the HLM of Thai student teacher appropriate Internet use behaviour 


\section{$3 \quad$ Methodology}

\subsection{Population and sample}

The population was student teachers studying for their bachelor's degrees at government educational institutions across Thailand in 2014. Multistage random sampling was used to acquire the sample group of 1,800 student teachers, which consisted of $60 \mathrm{stu}$ dent teachers from each of 30 Thai educational institutions. This number was classified equally by type of institution and their programs with 900 student teachers from Rajabhat universities, and 900 student teachers from government universities. Moreover, 900 were in computer or information technology programs, and 900 were from other programs. Furthermore, gender was evenly divided with 900 male and 900 female students. For further clarification to the reader, Thailand's Rajabhat university system is made up of approximately 540,000 students and was originally formed as institutes to produce teachers [26] - [27]. In 2005, Thailand's king elevated the institutes to universities and in 2020 there were 38 'Rajabhats' in total in Thailand.

\subsection{Research tools}

The researchers created a questionnaire about appropriate Internet use behaviour of Thai student teachers, which contained Figure 1's independent and dependent variables. The questionnaire was adapted and revised from a questionnaire about learning behaviours through electronic systems and other relevant information about high school students [1], [17], [20], [25].

The questionnaire contained two parts, including Part 1's 60 items concerning Thai student teacher appropriate Internet use behaviour. Moreover, this section was subdivided into eight sub-aspects as follows:

1. Internet use behaviour for learning, which consisted of three sub-aspects: Internet use for learning to follow instructions, Internet use for extra learning, and Internet use for self-learning.

2. Ethical Internet use behaviour, which consisted of five sub-aspects: no infringement on other ownership, no infringement on public, self-prevention from being infringed on, and prevention of self-harm.

Part 2 contained 96 items divided amongst the following four sub-aspects:

1. Information on each student teacher including aspects concerning their ability, affect, and general information

2. Information on home and family

3. Information on friends

4. Information on educational institutions and professors.

Each questionnaire item used a 6 - level rating scale (except for each student teacher's general information, which consisted of subjective questions). The rating scale is shown in Table 1 . The content validity and the reliability was examined by the 
researchers by executing a pre-test amongst 102 Thai student teachers studying for their bachelor's degrees in 2014 who did not participate in the subsequent study. The results showed that the reliability of the questionnaire $(\alpha)$ was $0.83-0.96$ which is considered good to excellent [28].

Table 1. Thai student teacher value criteria $(\bar{x})$

\begin{tabular}{|c|l|}
\hline Average $\overline{\boldsymbol{x}}$ range & \multicolumn{1}{|c|}{ Behaviour level } \\
\hline $5.50-6.00$ & Very appropriate \\
\hline $4.50-5.49$ & Appropriate \\
\hline $3.50-4.49$ & Fairly appropriate \\
\hline $2.50-3.49$ & Less appropriate \\
\hline $1.50-2.49$ & Least Appropriate \\
\hline $1.00-1.49$ & Inappropriate \\
\hline
\end{tabular}

\subsection{Data collection}

Data were collected by research assistants and the researcher network at each of the study's targeted university systems, which included 900 student teachers from Rajabhat universities and 900 student teachers from government universities (1,800 total). Moreover, the total sample was further classified equally into sub-groups by type of institution and program, with 900 student teachers from a university information and communications technology (ICT) program and 900 from other programs. All questionnaires were returned.

\subsection{Data analysis}

The level of appropriate Internet use behaviour of student teachers was analysed with the mean $(\bar{x})$, standard deviation (S.D.), using SPSS Version 21, with $\alpha$ values interpreted using the scale shown in Table 2 . Instrument reliability results are shown in Table 2 .

Table 2. Instrument reliability

\begin{tabular}{|l|c|c|c|c|}
\hline \multicolumn{1}{|c|}{ Variables } & Scale & Items & Validity & Reliability $(\boldsymbol{\alpha})$ \\
\hline Appropriate Internet use behaviour & 6-level scale & 60 & Good & 0.92 \\
\hline Ability & 6-level scale & 20 & Good & 0.92 \\
\hline Affective & 6-level scale & 32 & Good & 0.88 \\
\hline Family situation & 6-level scale & 8 & Good & 0.83 \\
\hline Institution situation & 6-level scale & 17 & Good & 0.96 \\
\hline Professors & 6-level scale & 9 & Good & 0.87 \\
\hline Friends & 6-level scale & 10 & Good & 0.89 \\
\hline & Total/Average & 156 & & \\
\hline
\end{tabular}




\section{$4 \quad$ Results}

Results from the personal characteristics of the first part of each Thai student teacher's questionnaire showed that male and female study participants were matched evenly, which was accomplished by design. Also, overwhelmingly, the student teachers identified their home as the most likely place where they used the Internet for research (65.5\%). Additionally, $41.22 \%$ indicated that their GPAs ranged between 3.00 - 3.49.

Additionally, the two-level HLM was created using the HLM 7 software program [29], from which the researchers identified three types of two-level models used in the analysis. These included:

1. An unconditional model which was a model of the dependent variables of Thai student teacher appropriate Internet use behaviour.

2. An unconditional model which was a two - level model that used only the first-level independent variable, which was the same level as the dependent variable, the student level, as the predictive variable, and selected only the independent variables influencing the dependent variable with statistical significance $(p \leq .05)$.

3. A hypothetical model was also a two-level model that used the first and second-level independent variables, student and institutional level, respectively, as the predictive variables.

The criteria for R2 interpretation of the independent variables towards the dependent variables in the unconditional model analysis contained independent variables at the student level (Table 3). Furthermore, the hypothetical model analysis contained independent variables at both the student and institution level. Table 4 shows the $\bar{x}$, S.D., skewness, and kurtosis of the variables.

Table 3. Criteria for $\mathrm{R} 2$ interpretation

\begin{tabular}{|c|c|l|}
\hline Predictive Coefficient $\left(\mathbf{R}^{2}\right)$ & Percentage (\%) & \multicolumn{1}{|c|}{ Predictive level } \\
\hline $\mathbf{R}^{2} \geq 0.49$ & From 49 & High \\
\hline $0.09 \leq \mathbf{R}^{2}<0.49$ & From 9 but lower than 49 & Moderate \\
\hline $\mathbf{R}^{2}<0.09$ & Lower than 9 & Low \\
\hline
\end{tabular}

Table 4. The $\bar{x}$, S.D., skewness, and kurtosis of variables

\begin{tabular}{|l|c|c|c|c|}
\hline \multicolumn{1}{|c|}{ Variables } & $\overline{\boldsymbol{x}}$ & S.D. & Skewness* & Kurtosis** \\
\hline Appropriate Internet use behaviour & 4.86 & .52 & -.73 & .60 \\
\hline Ability & 4.86 & .61 & -.71 & .84 \\
\hline Affective & 4.58 & .66 & -.34 & .17 \\
\hline Family situation & 4.60 & .87 & -.99 & 1.40 \\
\hline Institution situation & 4.36 & .89 & -.88 & .89 \\
\hline Professors & 4.67 & .69 & -.76 & 1.05 \\
\hline Friends & 4.87 & .72 & -.56 & 3.03 \\
\hline
\end{tabular}

*Skewness $<|1|[30], * *$ Kurtosis $<|7|[31]$ 


\subsection{HLM of Thai student teacher appropriate internet behaviour}

The HLM 7 software program was used to develop three model types on appropriate Internet use behaviour of student teachers. These included a dependent variable model, a model with independent variables at the student level, and a model with independent variables at the student and institutional levels.

\subsection{Appropriate internet behaviour of Thai student teachers}

Table 5 shows the analysis results of Thai student teacher appropriate Internet use behaviour by aspect, with overall appropriate Internet use. Moreover, ethical Internet use behaviour and Internet use for learning. Table 6 shows the correlations between appropriate Internet use behaviour and the independent variables.

Table 5. Thai student teacher appropriate Internet behaviour $\bar{x}$, S. D., and rank of student teacher behaviour by aspect

\begin{tabular}{|c|c|c|c|c|}
\hline \multirow[t]{2}{*}{ Appropriate Internet use behaviour } & \multicolumn{2}{|c|}{$\begin{array}{c}\text { Student Teach- } \\
\text { ers } \\
(n=1,800)\end{array}$} & \multirow[t]{2}{*}{ Level } & \multirow[t]{2}{*}{ Rank } \\
\hline & $\overline{\bar{x}}$ & S.D. & & \\
\hline Internet use behaviour for learning & 4.75 & .56 & Appropriate & 2 \\
\hline Following the teacher's Internet use behaviour instructions & 4.74 & .56 & Appropriate & 2 \\
\hline Internet use behaviour in other subjects & 4.63 & .70 & Appropriate & 3 \\
\hline Internet use behaviour for self-learning & 4.90 & .72 & Appropriate & 1 \\
\hline Ethical Internet use behaviour & 4.98 & .62 & Appropriate & 1 \\
\hline Not violating the privacy of others & 5.19 & .78 & Appropriate & 1 \\
\hline Not violating other's ownership & 4.98 & .80 & Appropriate & 3 \\
\hline No public infringement of others & 5.18 & .78 & Appropriate & 2 \\
\hline Self-protection of channels from others & 4.78 & .77 & Appropriate & 4 \\
\hline Prevention of self-harm & 4.75 & .79 & Appropriate & 5 \\
\hline Average & 4.86 & .52 & Appropriate & - \\
\hline
\end{tabular}

Table 6. Correlations between appropriate Internet use behaviour and independent variables

\begin{tabular}{|l|c|c|c|c|c|c|c|}
\hline \multicolumn{1}{|c|}{ Variables } & $\mathbf{1}$ & $\mathbf{2}$ & $\mathbf{3}$ & $\mathbf{4}$ & $\mathbf{5}$ & $\mathbf{6}$ & $\mathbf{7}$ \\
\hline 1. Appropriate Internet use behaviour & - & $.69^{* *}$ & $.53^{* *}$ & $.49^{* *}$ & $.41^{* *}$ & $.59^{* *}$ & $.61^{* *}$ \\
\hline 2. Ability & & - & $.59^{* *}$ & $.53^{* *}$ & $.39^{* *}$ & $.55^{* *}$ & $.61^{* *}$ \\
\hline 3. Affective & & & - & $.52^{* *}$ & $.47^{* *}$ & $.54^{* *}$ & $.51^{* *}$ \\
\hline 4. Family situation & & & & - & $.42^{* *}$ & $.48^{* *}$ & $.51^{* *}$ \\
\hline 5. Institution situation & & & & & - & $.70^{* *}$ & $.35^{* *}$ \\
\hline 6. Professors & & & & & & - & $.51^{* *}$ \\
\hline 7. Friends & & & & & & & - \\
\hline
\end{tabular}

Note. $* * p<.01$ 


\subsection{Dependent variable model of appropriate internet use behaviour in student teachers}

The dependent variable model of appropriate Internet use behaviour in teacher students was a fully unconditional model. Details of the analysis results are as shown in Table 7, which indicates the fixed effects and random effects in the dependent variable model as follows:

1. The analysis results of fixed effects using t-test showed that the INTRCPT, which was the mean of teacher student behaviour or grand mean, had positive effects on the dependent variables of appropriate Internet use behaviour in student teacher in the institution, with statistical significance at the .01 level and the coefficient at 4.865, which was significant.

2. The analysis results of random effects using $\left(\chi^{2}\right.$-test) indicated that the mean of dependent variables of teacher student behaviour was different between the institutions, with statistical significance at the .01 level and variance of 0.074 . Moreover, the score of behaviour between the personnel in the institution was determined, with the variance of 0.204 being calculated, which resulted in a total variance at 0.278 . It could be seen that most of the variance of appropriate Internet use behaviour in student teachers were among the students, accounting for $73.296 \%$, while it was only $26.704 \%$ for the variance between the institutions.

Table 7. Analysis results of the dependent variable model of appropriate Internet use behaviour of Thai student teachers

\begin{tabular}{|c|c|c|c|c|c|}
\hline Fixed Effect & Coefficient & Standard error & $t$-ratio & Approx.d.f & $p$-value \\
\hline \multicolumn{6}{|c|}{ For INTRCPT1, $\beta_{0}$} \\
\hline INTRCPT $2, \gamma_{00}$ & 4.864739 & 0.049995 & 97.304 & 29 & $<0.001$ \\
\hline Random Effect & Standard Deviation & $\begin{array}{l}\text { Variance Compo- } \\
\text { nent }\end{array}$ & d.f. & $\chi^{2}$ & $p$-value \\
\hline INTRCPT $1, u_{0}$ & 0.27236 & 0.07418 & 29 & 662.89697 & $<0.001$ \\
\hline level-1, $r$ & 0.45123 & 0.20361 & & & \\
\hline
\end{tabular}

These results illustrate that the dependent variables of appropriate Internet use behaviour in student teachers could be explained by independent variables at the student and institution levels. Therefore, an analysis of the model with independent variables proceeded.

\subsection{Unconditional model with independent variables at the student level}

In the unconditional model, behaviour was the dependent variable, and the independent variable was at the student level, with the first independent variable predicting the dependent variable with statistical significance. Therefore, the analysis results of the fixed effect and random effect in the model are as follows:

1. The analysis results of fixed effect using t-test showed that the INTRCPT, which was the mean of appropriate Internet use behaviour in student teachers in the institutions and the five variables at the student level (ability, affect, family, gender, and 
$G P A$ ), with all having positive effects on the dependent variables of the behaviour, with statistical significance at the .01 level, coefficient of 4.865 , and regression coefficient of the ability, affect, family, gender, GPA, and income of 0.369, 0.123, $0.081,0.063$, and 0.041 , respectively. The income of the student teachers had negative effects on the dependent variables, with statistical significance at the .01 level, with a regression coefficient of -0.011 . Independent variables explained the variance of dependent variables of behaviour at a high level, accounting for $52.262 \%$.

2 . The analysis results also showed the random effect using the $\chi^{2}$-test, which indicated that the fixed effect and the five independent variables had an average of 0.078 of variance at the institution level with statistical significance at the .01 level. Ability, affect, family, gender, and GPA had variances of 0.025, 0.027, 0.005, 0.008, and 0.004 , respectively. It could be assumed that the independent variables at the institution level could explain the variables. For income, the remaining variance had no statistical significance, while it was 0.097 at the student level.

\subsection{The hypothetical model with independent variables at the student and institution levels}

The hypothetical model testing was concerned with the dependent variables of Thai student teacher appropriate Internet use behaviour, as well as the independent variables at the student and institution levels which were the first and second level variables, respectively. Testing results determined that the variables at each level predicted the dependent variables with statistical significance. Figure 2 depicts the analysis results of fixed effect and random effect in the hypothetical model, whose results can be stated as follows:

Analysis results of the fixed effect using t-test showed that the INTRCPT of institution level, which was the mean of teacher student behaviour at the institution level and the variable at the institution level friends, had a positive effect on the dependent variable behaviour, with statistical significance at the .01 level, a coefficient of 4.833 , and a regression coefficient for friends of 0.807 . This explains the variance of mean of behaviour at a high level, $94.222 \%$.

Moreover, the regression coefficient of the Thai student teacher aspect for ability, affect, family, gender, GPA, and income were $0.373,0.124,0.081,0.063,0.042$, and 0.011 , respectively. There was one independent variable at the institution level, which was the institution situation, explaining the regression coefficient of ability at 11.472 with statistical significance at the .05 level. The regression coefficient of institution situation at the institution level was 0.144 .

Furthermore, the analysis results of random effect using $\left(\chi^{2}\right.$-test) indicated that the fixed effect and the five independent variables had the remaining variance at the institution level with a statistical significance at the .01 level. The remaining variance of fixed effect was 0.004, with the Thai student teacher aspects of ability, affect, family, gender, and GPA having remaining variances at 0.022, 0.027, 0.005, 0.008, and 0.004, respectively. It could be assumed that the independent variables at the institution level could explain the variables. For income, the remaining variance had no statistical significance, while it was 0.097 at the student level. 


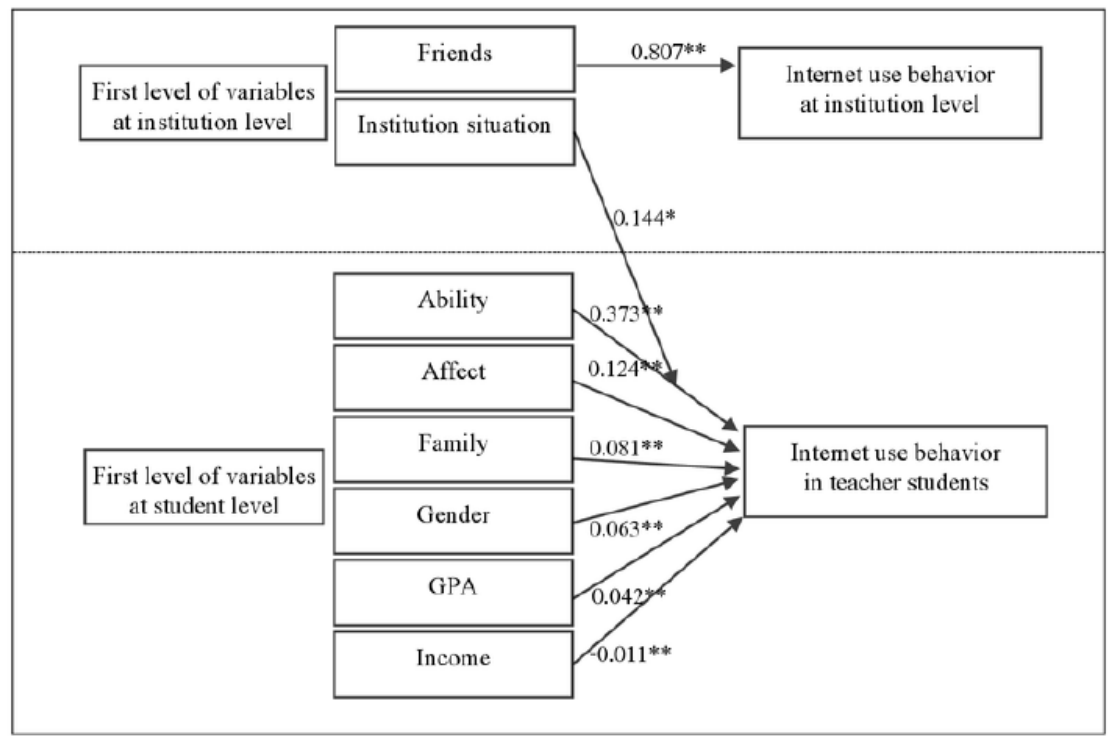

Fig. 2. HLM model of Thai student teacher appropriate Internet use behaviour

\subsection{Level of appropriate internet use of Thai student teachers}

From the 1,800 Thai student teachers examined, the findings revealed that the Internet use behaviour of Thai student teachers was classified as 'appropriate' $(\bar{x}=4.86$, S.D. $=0.52$ ). This was possibly because the respondents in this research were student teachers who had experience in using the Internet in both educational environments as well as higher education.

Moreover, the study's findings were in line with the research of [32], which determined that the driving force behind the contemporary educational process is technological development. Therefore, the quality of human capital professional creativity competencies is determined by student knowledge and their ability to acquire it from various university sources, with advanced Internet use in the teaching process leading to a higher level of human capital professional creativity competencies.

\subsection{HLM of appropriate internet use behaviour of Thai student teachers}

The analysis results of the HLM of appropriate Internet use behaviour in student teachers showed that their behaviour was affected by two-levels of predictive variables, including six variables at the student level and two variables at the institution level. These were ability (0.302), affect (0.124), family (0.081), gender (0.063), GPA (0.042), and income (-0.011) at the student level and friends (0.807) and institutional situation $(0.144)$ at the institution level.

These findings are similar to research in Turkey in which it was determined that problematic Internet use (PIU) was associated with being male, having a low GPA, 
Internet use frequency, and the student's family income level [33]. These findings were also consistent with the variables in previous research by [34] - [36]. Moreover, all predictive variables had a positive effect on behaviour except for income, which was determined to negatively affect appropriate Internet use behaviour when the student's family had a low income. The study also determined that ability, affect, and friends acted as predictive variables which are consistent with other studies from [14] - [15]. Furthermore, there was evidence that institutional support, either from the teacher's education program or the school community, positively impacts teacher student beliefs, indirectly influencing their technology integration behaviours [37].

This is consistent with [38] who also elaborated on the positive effects of ICT resources and the importance of teachers who believed in student-cantered learning. Additionally, this is in line with research from [39], who studied the predictive relationship between student teacher attributes and the teaching behaviour of students in Bangkok schools and found that the student attributes that could predict their teaching behaviour were work motivation, the relationship between teachers and students, attitude towards the teaching profession, the relationship between teachers and colleagues and executives, and students' personality.

This is consistent with the study's findings in which ability was determined to be comprised of various sub-aspects, including Internet knowledge and skills. This was consistent with [14] who indicated that a preservice teacher's self-efficacy of the use of technology had the greatest effect on technology use. Also, knowledge and ability in using technology to enhance learning can often times be the core problem in the development of technology use potential in students [40].

Furthermore, the study determined that a student's family situation had a positive effect on a student teacher's appropriate Internet use behaviour, especially if the student's home was equipped with a computer and the Internet, with family support fostering appropriate Internet use behaviour. Today, however, smartphones and social media platforms are becoming more prevalent [24], from which social media participation has been reported to have many benefits for students. These tools, however, have the potential to negatively impact academic performance if not used properly [41].

Moreover, the study has determined that gender had a positive effect on appropriate Internet use behaviour. In Turkey, [42] detailed numerous studies which discussed the effects of gender on student education and ICT use and integration, and overall, from the study of 600 teachers believed that even though men are seen as more proficient in ICT, women are more willing to spare the required time for planning technology. There are other studies in the literature that similarly report a higher proportion of technology use and technology integration in men compared to women [43] - [44].

GPA was also determined to have a positive effect on the appropriate Internet use behaviour of student teachers, which was consistent with the findings from a Bangkok study in which Internet use by high school students had a positive effect on GPA Additional researchers have also found a strong correlation between Internet use and academic performance [46]; with high school students having reported that not being able to control their Internet usage has impacted their academic work negatively [47].

Furthermore, results showed that the student teacher's income aspect had a negative influence on their appropriate Internet use behaviour, although calculated very low as 
the influence was 0.011. Maybe it was because student teachers with low incomes don't have restrictions on using the Internet, since higher education institutions provide appropriate services and support for using the Internet. Therefore, students, although having less income, have the opportunity to access and use the Internet more. In addition, student teachers have already had the opportunity to acquire basic knowledge and skills that are appropriate.

Since the analysis results of the random effect in the model with two-level predictive variables, student and institutional level (hypothetical model), illustrated that there was a remaining dependent variance of appropriate Internet use behaviour in students at the institutional and student level, it was assumed that the predictive variable could be added to these variables to explain the variance. Additionally, the regression coefficients of ability, affect, family, gender, and GPA still had the remaining variance. Thus, more predictive variables could be added as well.

\section{$5 \quad$ Recommendations}

Faculties of Education, institutions of education, original affiliations, and relevant agencies and educational institutions for teacher student development must continue development of a Thai student teacher's ability and affect by focusing on student competence in the acquisition of basic knowledge and skills in ICT. Additionally, there needs to be a focus on student psychological qualities attributes including attitude towards the use of ICT, achievement motivation, and intellectual retention.

The results also showed that student teachers' ability and affect had a positive effect on their appropriate Internet use behaviour. Therefore, teachers can facilitate the learning process and make it more productive by using technology to support pedagogical strategies they use for transferring content information [42].

Furthermore, education colleges and institutions should supply material for instructional planning and teacher student learning, support and strengthen teacher students to use IT media, and provide funding for supporting experience in using IT media in instructional planning. With this support, student teachers have the opportunity to learn and enhance themselves in using IT, which definitely leads to the appropriate use of ICT in instructional planning.

Friends had an influence on the appropriate Internet use of student teachers, so friends who use social media appropriately can be helpful in promoting appropriate Internet use behaviour. For this reason, education colleges and institutions should promote teacher networking and provide resources and facilities to help with the appropriate use of ICT media.

Additionally, institutional situations had a positive effect on appropriate Internet use behaviour. Institutional reinforcement can come through a variety of methods including administrator and management support for ICT facilities, support for the use of ICT media resources and equipment, publication of ICT school achievement and resources, and assisting other schools in their own development of ICT facilities and resources. Schools should, therefore, support computer and ICT readiness, while also supporting teachers' use of ICT media in teaching and development [48] - [49]. 
Moreover, educational policies should focus on emphasizing teacher competency development in terms of knowledge, skills, and attributes, through training and/or seminars with professional instructors. Finally, student teachers should have the opportunity to interact with friends in various forms, such as cooperative learning, learning together, and learning exchange, including networks of ICT usage at the student and institution levels.

\section{Recommendations for Further Research}

Future research should include more independent variables in the model, both at the student and institutional levels to explain the variance of dependent variables of appropriate Internet use behaviour in students, particularly independent variables affecting individual behaviour. This is because appropriate Internet use behaviour in students has a variance at the individual level of $73.246 \%$. Other variables that should be examined are knowledge and skills in curriculum and teaching, attitude toward the teaching profession, readiness for change, and self-learning. It is also suggested that a student's workload, interaction with student teachers and students, interaction with institution executives, patterns/approaches and policies/plans of institutions supporting the use of ICT of students, school websites, and software for instructional planning be examined.

The variables affecting appropriate Internet use behaviour in student teachers should be studied using the research model and other types of casual analysis models, such as with SEM and 3-level HLM 7 models, which are more complex.

The HLM should be applied to other variables in the educational system. This may include variables in student teachers, administrators, or students. It would be very useful to acquire deeper and broader knowledge within these areas.

There should be an in-depth study on the details of basic knowledge and skills in computers, the Internet, ICT usage, and the effects of social media that needs to be developed in the different groups of teachers according to their variables, such as subject/department, teaching level, and institution situations. This would assist teachers in setting instructional plans.

\section{$7 \quad$ References}

[1] P. Leekitchwatana and P. Pimdee. "Appropriate Thai high school student Internet behaviour: A Hierarchical Linear Model analysis," International Journal of Emerging Technologies in Learning, vol. 12, no. 10, pp. 158 - 172, 2017. https://doi.org/10.3991/ijet.v12i10.7366

[2] F. Akar, "Purposes, causes and consequences of excessive Internet use among Turkish adolescents," Eurasian Journal of Educational Research, vol. 15, no. 60, pp. 35 - 56, 2015. https://doi.org/10.14689/ejer.2015.60.3

[3] J. Ferquest, "Games addiction: 2.7 million Thai children," Bangkok Post. 15 Oct., 2013. [Online]. Available: https://tinyurl.com/sspvun9. [Accessed Jul. 11, 2020].

[4] S. Kanbul, T. E. Kallagov, V. E. Rubanik, E. R. Khairullina, and L. A. Ribakova, "Determination of mobile addiction and social media addiction level of parents and their attitudes towards usage of technology," International Journal of Emerging Technologies in Learning, vol. 14, no. 22, pp. 175 - 190, 2019. https://doi.org/10.3991/ijet.v14i22.11770 
[5] W. S. Nuankaew, P. Nuankaew, D. Teeraputon, K. Phanniphong, and S. Bussaman, "Perception and attitude toward self-regulated learning of Thailand's students in educational data mining perspective." International Journal of Emerging Technologies in Learning, vol. 14, no. 8, pp. 34 - 49, 2019. https://doi.org/10.3991/ijet.v14i09.10048

[6] Internet Society, "Internet Access and Education: Key considerations for policy makers," 20 Nov. 2017. [Online]. Available: https://tinyurl.com/y8nugm2m [Accessed Jul. 11, 2020].

[7] O. Zawacki-Richter, E. M. Bäcker, and S. Vogt, "Review of distance education research (2000 to 2008): Analysis of research areas, methods, and authorship patterns," The International Review of Research in Open and Distributed Learning, vol. 10, no. 6, pp. 21 - 50, 2009. https://doi.org/10.19173/irrodl.v10i6.741

[8] D. Langford, "Ethics and the Internet: Appropriate behaviour in electronic communication," Ethics \& Behaviour, vol. 6, no. 2, pp. 91 - 106. 1996. https//doi.org/10.1207/s15327019 eb0602_2

[9] O. Palesh, K. Saltzman, and C. Koopman, "Internet use and attitudes towards illicit Internet use behaviour in a sample of Russian college students," Cyber Psychology \& Behaviour, vol. 7, no. 5, pp. 553 - 558, 2004. https://doi.org/10.1089/cpb.2004.7.553

[10] P. M. Yellowlees and S. Marks, "Problematic Internet use or Internet addiction?" Computers in Human Behaviour, vol. 23, no. 3, pp. 1447 - 1453, 2007. https://doi.org/10.1016/j.chb. $\underline{2005.05 .004}$

[11] M. Nelson, "The role of a mentor teacher's TPACK in preservice teachers' intentions to integrate technology. Journal of Technology and Teacher Education, vol. 25, no. 4, pp. 449473, 2017. [Online]. Available: https://tinyurl.com/yxda5sdw [Accessed Jul. 11, 2020].

[12] H. Woltman, A. Feldstain, J. C. MacKay, and M. Rocchi, "An introduction to hierarchical linear modelling," Tutorials in Quantitative Methods for Psychology, vol. 8, no. 1, pp. 52 69, 2012. https://doi.org/10.20982/tqmp.08.1.p052

[13] N. Wiratchai, Linear structural relations (LISREL) statistical analysis for the behavioural sciences and social sciences research. Bangkok, Thailand: Chulalongkorn University Printing, 1995.

[14] R. J. Chen, "Investigating models for preservice teachers' use of technology to support student-centered learning," Computers \& Education, vol. 55, no. 1, pp. 32 - 42, 2010. https://doi.org/10.1016/j.compedu.2009.11.015

[15] F. A. Inan and D. L. Lowther, "Factors affecting technology integration in K-12 classrooms: A path model," Educational Technology Research \& Development, vol. 58, no. 2, pp. 137 154, 2010. https://doi.org/10.1007/s11423-009-9132-y

[16] D. Bhanthumnavin, "Research on behavioural science for individual and society development. Document for meeting the use and production of behavioural science research for benefits of Thai society," Bangkok, Thailand: National Research Council of Thailand, 2005.

[17] B. Stodt, E. Wegmann, E., and M. Brand, "Predicting dysfunctional Internet use: The role of age, conscientiousness, and Internet literacy in Internet addiction and cyberbullying". International Journal of Cyber Behaviour, Psychology and Learning, vol 6, no 4, pp. 28 - 43, 2016. https://doi.org/10.4018/ijcbpl.2016100103

[18] J. Castiglione, "Internet abuse and possible addiction among undergraduates: A developing concern for library and university administrators," Library Review, vol 57, no 5, pp. 358 371, 2008. https://doi.org/10.1108/00242530810875140

[19] S. S. Guan and K. Subrahmanyam, "Youth Internet use: risks and opportunities". Current Opinions in Psychiatry, vol 4, pp. 351 - 356, 2009. https://doi.org/10.1097/yco. $\underline{0 \mathrm{~b} 013 \mathrm{e} 32832 \mathrm{bd} 7 \mathrm{e} 0}$ 
[20] M. Dečman, "Modeling the acceptance of e-learning in mandatory environments of higher education: The influence of previous education and gender," Computers in Human Behaviour, vol 49, pp. 272 - 281, 2015. https://doi.org/10.1016/j.chb.2015.03.022

[21] X. Dong, "Searching information and evaluation of internet: a Chinese academic user survey”, International Information \& Library Review, vol. 35, nos. 2-4, pp. 163-87, 2003. https://doi.org/10.1080/10572317.2003.10762599

[22] J. Finn, "A survey of online harassment at a university campus," Journal of Interpersonal Violence, vol. 19, no. 4, pp. 468 - 483, 2004. https://doi.org/10.1177 /0886260503262083Actions. https://doi.org/10.1177/0886260503262083

[23] A. Gelpi, "Was a university liable for a professor's sexual harassment of students?" Campus Legal Advisor, vol. 16, no. 1, pp. 15 - 15, 2015. https://doi.org/10.1002/cala.30188

[24] Digital Thailand Report 2019. [Online]. Available: https://tinyurl.com/qn6vxm2 [Accessed Jul. 11, 2020].

[25] G. Ben-Zadok, M. Leiba, and R. Nachmias, "Comparison of online learning behaviours in school vs. at home in terms of age and gender based on log file analysis". Interdisciplinary Journal of E-Learning and Learning Objects, vol. 6, no. 1, pp. 305-322, 2010. https:// doi.org/10.28945/1317

[26] Rajabhat enrolments 'shrinking' Bangkok Post. (Fe. 2, 2018). [Online]. Available: https://tinyurl.com/y 5 qqsc8s [Accessed Jul. 11, 2020].

[27] Rajabhat Institutes Act, B.E. 2538 (1995). [Online]. Available: https://tinyurl.com/y5xvxcc9 [Accessed Jul. 11, 2020].

[28] M. Tavakol and R. Dennick, "Making sense of Cronbach's alpha," International Journal of Medical Education, vol. 2, pp. 53 - 55, 2011. [Online]. Available: https://doi.org/10.5116/ijme.4dfb.8dfd [Accessed Jul. 11, 2020].

[29] S. W. Raudenbush and A. S. Bryk, Hierarchical Linear Models: Applications and Data Analysis Methods. Newbury Park, CA: Sage, 2002.

[30] J. F. Hair, W. C. Black, B. J. Babin, B. J., and R. E. Anderson, Multivariate Data Analysis. New Jersey: Pearson Prentice Hall, 2009.

[31] P. J. Curran, S. G. West, and J. F. Finch, "The robustness of test statistics to nonnormality and specification error in confirmatory factor analysis," Psychological Methods, vol. 1, no. 1, pp. 16 - 29, 1996. https://doi.org/10.1037/1082-989x.1.1.16

[32] A. Sokół, I. Figurska, I., and M. Blašková, "Using the Internet to enhance teaching Process at universities for the development of creativity competencies," Procedia-Social and Behavioural Sciences, vol. 186, pp. 1282 - 1288, 2015. https://doi.org/10.1016/j.sbspro. $\underline{2015.04 .036}$

[33] V. Demirer and B. Bozoglan, "Purposes of Internet use and problematic Internet use among Turkish high school students," Asia-Pacific Psychiatry, vol. 8, no. 4, pp. 269 - 277, 2016. https://doi.org/10.1111/appy.12219

[34] H-P. Yueh, T-L. Chen, L-A. Chiu, and W-C. Lin, "Exploring factors affecting learner's perception of learning information and communication technology: A HLM analysis of a national farmers' training program in Taiwan," Journal of Educational Technology \& Society, vol. 16, no. 1, pp. 231 - 242, 2013. [Online]. Available: https://tinyurl.com/ y6ysehob [Accessed Jul. 11, 2020].

[35] M. Büchi, N. Just, and M. Latzer, "Modeling the second-level digital divide: A five-country study of social differences in Internet use," New Media \& Society, vol. 18, no. 11, pp. 2703 - 2722, 2016. https://doi.org/10.1177/1461444815604154

[36] S-H. Liu, "A multivariate model of factors influencing technology use by preservice teachers during practice teaching, "Educational Technology \& Society, vol. 15, no. 4, pp. $137-149$, 2012. https//doi.org/10.1007/s10639-018-09859-y 
[37] S. Chomphupart, "Development of causal model of using information and communication technology in teachers' instructional practices,” M. A. thesis, Chulalongkorn University, Bangkok, Thailand, 2005.

[38] K. F. Hew and C. Y. Tan, "Predictors of information technology integration in secondary schools: Evidence from a large-scale study of more than 30,000 students," PLOS ONE, vol 11, no. 12, pp. 1 - 20, 2016. https://doi.org/10.1371/journal.pone.0168547

[39] A. Somjai, "Study on the relationship between teacher characteristics and teaching behaviour of teacher in school under Office of Bang Kapi District," M.A. thesis. Bangkok, Thailand: Ramkhamhaeng University, 2006.

[40] A. M. Johnson, M. E. Jacovina, D. E. Russell, and C. M. Soto, "Challenges and solutions when using technologies in the classroom," in Adaptive educational technologies for literacy instruction, S. A. Crossley and D. S. McNamara, eds. New York: Taylor \& Francis, 2016, pp. 13 - 29. https://doi.org/10.4324/9781315647500-2

[41] M. Badri, A. A. Nuaimi, Y. Guang, and A. A. Rashedi, "School performance, social networking effects, and learning of school children: Evidence of reciprocal relationships in Abu Dhabi," Telematics and Informatics, vol. 34, no. 8, pp. 1433 - 1444, 2017. https://doi.org/10.1016/j.tele.2017.06.006

[42] Ö Uslu, "Factors associated with technology integration to improve instructional abilities: A path model. Australian Journal of Teacher Education, vol. 43, no. 4, 31 - 50, 2018. https://doi.org/10.14221/ajte.2018v43n4.3

[43] R. Hermans, J. Tondeur, J. van Braak, and M. Valcke, "The impact of primary school teachers' educational beliefs on the classroom use of computers," Computers \& Education, vol. 51, no. 4, pp. 1499 - 1509, 2008. https://doi.org/10.1016/j.compedu.2008.02.001

[44] J. Tondeur, M. Valcke, and J. Van Braak, "A multidimensional approach to determinants of computer use in primary education: Teacher and school characteristics," Journal of Computer Assisted Learning, vol. 24, no. 6, pp. 494 - 506, 2008. https://doi.org/10.1111/ j.1365-2729.2008.00285.x

[45] T. Vathaniyanont, "Relationships between using Internet behaviours and learning achievement of upper secondary school students," M. A. thesis, Chulalongkorn University, Bangkok, Thailand, 1999.

[46] R. W. Kubey, M. J. Lavin, and J. R. Barrows, Internet use and collegiate academic performance decrements: The early findings," Journal of Communications, vol. 51, no. 2, pp. 366 - 382, 2001. https://doi.org/10.1111/j.1460-2466.2001.tb02885.x

[47] S. Mishra, P. Draus, N. Goreva, G. Leone, and D. Caputo, "The impact of Internet addiction on university students and its effect on subsequent academic success: A survey-based stud," Issues in Information Systems, vol. 15, no. I, pp. 344-352, 2014. [Online]. Available: https://tinyurl.com/yce4rrmy [Accessed Jul. 11, 2020]. https://doi.org/10.48009/ 1 iis_2014_344-352

[48] W. Banyen, C. Viriyavejakul, and T. Ratanaolarn, "A blended learning model for learning achievement enhancement of Thai undergraduate students". International Journal of Emerging Technologies in Learning, Vol 11 No 4, PP. 48 - 55, 2016. https://doi. org/10.3991/ijet.v11i04.5325

[49] T. Santhuenkeaw, S. Tontiwongwanich, and P. Pimdee, "Improving Thai student's digital media skills: An exploratory learning model," Revista Espacios, vol. 40, no. 15, pp. 21 - 35, 2019. [Online]. Available: https://tinyurl.com/y4kzcmpx [Accessed Jul. 11, 2020]. 


\section{Authors}

Punnee Leekitchwatana is an Associate Professor in the Faculty of Industrial Education and Technology at the King Mongkut's Institute of Technology Ladkrabang (KMITL), Bangkok, Thailand. She graduated with a B.Ed. and M.Ed. in science education and has an Ed.D. in curriculum research and development. She specializes in Educational Research, Science Education, Curriculum Development and Measurement / Evaluation in Education. E-mail: punnee.le@kmitl.ac.th

Paitoon Pimdee is an Associate Professor in the Faculty of Industrial Education and Technology at the King Mongkut's Institute of Technology Ladkrabang (KMITL), Bangkok, Thailand. He graduated with a Bachelor of Science (B.Sc.) in Chemistry, a Bachelor of Economics (B. Econ.) in Economics, and a Master of Science (M.Sc.) degree in science education. He has a Ph.D. in environmental education. He specializes in environmental issues, energy conservation, ecotourism, behavioral sciences, and education. He can be contacted at paitoon.pi@kmitl.ac.th

Article submitted 2020-02-13. Resubmitted 2020-07-10. Final acceptance 2020-07-10. Final version published as submitted by the authors. 